преподавателями, порождает также практику самоорганизации студентов, и эти принципы инициативного действия позволяют воспитать активных лидеров, развить структуры самоуправления и саморегулирования жизни кампуса.

В итоге, можно сделать вывод, что основные особенности проектирования университетских кампусов заключаются в следующем:

- организация пешеходной доступности всех сооружений комплекса;

- наличие территории для возможности последующего развития и расширения;

- организация гибкого внутреннего пространства, позволяющего перепланировку;

- нерегулярная расстановка зданий на территории кампуса;

- выделение рекреационного пространства в центре кампуса;

- расположение кампуса в живописной ландшафтной среде;

- использование гибких современных архитектурно-планировочных решений;

- высокий уровень развития инфраструктуры жилого сектора.

$$
* * *
$$

1. Пучков М.В. Архитектура университетских комплексов / М.В. Пучков. - Екатеринбург: Изд-во УрГУ, 2010

2. Рождественская Е.С. Принципы гармонизации антропогенной и природной среды / Вестник Оренбургского Государственного Университета. Специальный выпуск: Архитектура и дизайн. Теория и практика. - Выпуск № 11 (61). - Оренбург, 2006. - С. 198.

\title{
Хохолов Ю.А. \\ Тепловой расчет послойного намораживания пород при разработке полезных ископаемых в криолитозоне
}

Институт горного дела Севера им. Н.В. Черского СО РАН (Россия, Якутск)

doi: $10.18411 / l j-31-01-2018-57$

idsp: 000001:lj-31-01-2018-57

\section{Аннотация}

Приведены примеры применения технологии послойного намораживания пород в горном деле. Показано, что при разработке полезных ископаемых подземным способом оптимизация технологических параметров послойного намораживания позволяет формировать закладочный массив с необходимыми прочностными свойствами. Приведены примеры расчета послойного намораживания пород при строительстве мерзлой грунтовой плотины

Ключевые слова: Послойное намораживание, горные породы, льдопородная закладка, температура, влажность

Приведем отдельные результаты по моделированию тепловых процессов при формировании льдопородных массивов, имеющих практическую значимость при разработке полезных ископаемых в криолитозоне. Например, температурный режим рудников, расположенных в зоне распространения многолетней мерзлоты, позволяет формировать при отработке мерзлотных горизонтов ледяную или льдопородную закладку. Данный способ отработки отличается низкой стоимостью по сравнению с традиционными технологиями закладки выработанного пространства [1]. Более эффективным способом формирования льдопородного закладочного массива является его послойное намораживание. В ИГДС СО РАН разработана методика расчета послойного намораживания пород в горном деле для условий криолитозоны, которая позволяет оптимизировать технологические параметры формирования льдопородного массива с 
необходимыми прочностными свойствами. Оптимизация формирования льдопородной закладки состоит в минимизации времени послойного замораживания увлажненной породной смеси и является нестационарной, нелинейной и многопараметрической задачей. Для оптимизации процесса возведения закладочного массива разработана двухмерная математическая модель теплообмена рудничного воздуха с формируемой методом послойного намораживания льдопородной закладкой и окружающим массивом горных пород [2,3].

Как показывают расчеты (рис. 1), для заданной толщины единичного слоя существует оптимальное время замораживания, при котором общее время формирования закладочного массива минимально. Даже небольшое отклонение времени замораживания в сторону уменьшения ведет к резкому увеличению общего времени формирования закладочного массива. Увеличение продолжительности промораживания слоя, по сравнению с оптимальным, незначительно увеличивает общее время формирования закладки. Поэтому на практике время замораживания каждого слоя должно выбираться с некоторым запасом.

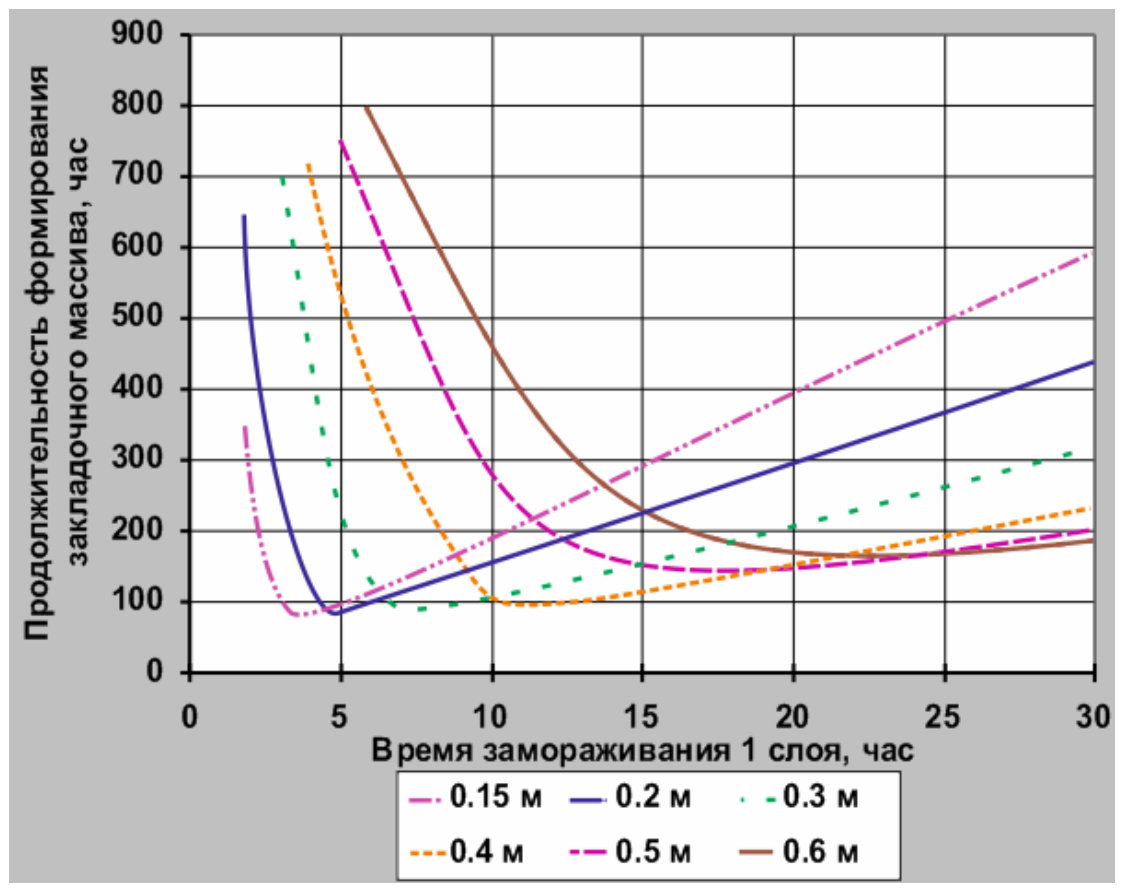

Рис. 1. Продолжительность формирования закладочного массива в зависимости от времени замораживания 1 слоя при разных значениях влажности укладываемого слоя.

Таким образом, оптимизация технологических параметров послойного намораживания при закладке выработанного пространства рудников позволяет формировать закладочный массив с необходимыми прочностными свойствами, способствуя тем самым повышению безопасности ведения горных работ и ускорению сроков отработки месторождения.

Отработка основных запасов россыпного алмазоносного месторождения «Горное» (Мирнинский район Республики Саха (Якутия), прииск "Ирелях" АК «АЛРОСА») предусмотрена дражным способом. Месторождение представляет собой типичную надпойменную террасовую россыпь отличительной особенностью, которой является ее значительная протяженность, и ширина с расположением значительной части запасов на разных гипсометрических уровнях, что требует четкой организации горно подготовительных, вскрышных, добычных и рекультивационных работ.

Для обеспечения доступа драги к промзапасам на месторождении «Горное» технологией работ предусмотрено строительство 15 плотин-котлованов с общей протяженностью дамб более 32 км. Дамбы сооружаются из пород вскрыши, 
укладываемых по подошве на плотик промзапасов. Технологией производства работ предусмотрено опережающее по времени вскрытие промблоков от торфов и выемка песков по всей протяженности контурных осей котлованов

В зависимости от начального значения отрицательной температуры кусков мерзлой породы и количества заливаемой воды слой влажных горных пород может быть заморожен за счет холода, аккумулированного в мерзлых кусках за различный период. Строительство дамб дражных котлованов предусматривается в зимний период (ноябрьмарт) из мерзлых вскрышных пород (суглинков). По условиям фильтрационной прочности дамбы устраиваются с врезкой зуба в коренные породы и оформлением ядра путем послойной укладки, укатки, дополнительного увлажнения до 25-30\% влажности и последующей проморозки каждого слоя в течение периода, определенного расчетом

Укладка льдопородной смеси производится в зимнее время и состоит из следующих технологических операций: раздробленные торфа доставляется на место строительства плотины (дамбы) и укладывается слоями снизу-вверх с проливом водой, распыляемой форсунками водовозки. После промораживания слоя атмосферным холодом сверху укладывается другой слой и так далее до необходимой высоты.

Для определения динамики формирования температурного поля льдопородного массива и основания плотины разработана математическая модель теплообмена атмосферного воздуха с возводимой льдопородной плотиной на основе параболических уравнений математической физики [4,5], которая учитывает все основные факторы: влажность (льдистость) отсыпаемых горных пород, толщину слоя, годовой ход наружной температуры воздуха и т.д.

Основным управляющим параметром при формирования льдопородного массива является время замораживания одного слоя при его заданной толщине. Время счета останавливается после укладки последнего слоя и при достижении температуры льдопородного массива заданного значения $\left(-5^{\circ} \mathrm{C}\right)$.

На основании расчетов получены зависимости времени промораживания одного слоя от температуры атмосферного воздуха, начальной температуры, влажности и толщины слоя. На рис. 2 приведены зависимости для одного из вариантов расчета.

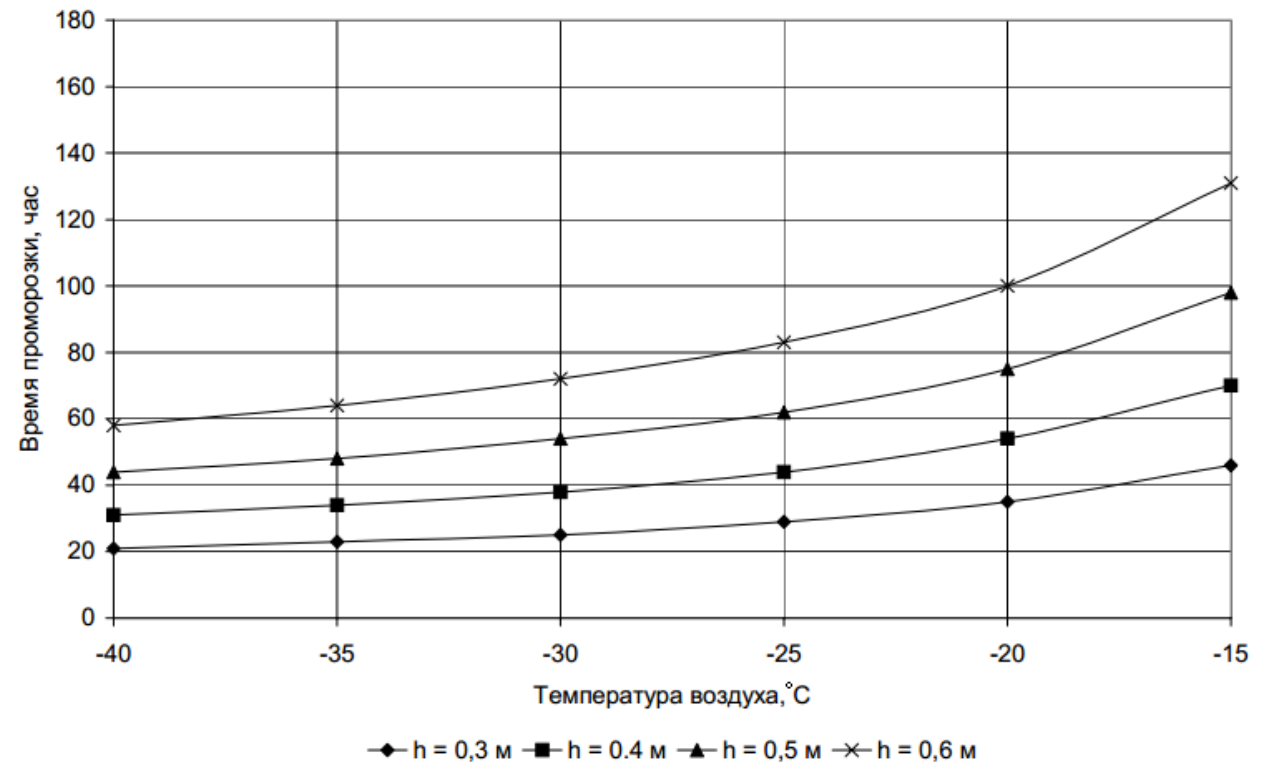

Рис. 2. Зависимости времени проморажсивания слоя от температуры атмосферного воздуха и толщины слоя. Начальная температура слоя $0^{\circ} \mathrm{C}$, расход воды $250 \mathrm{\pi} / \mathrm{M} 3$

Как показывают расчеты, наиболее существенное значение для промерзания слоя до заданной температуры, при прочих равных условиях, имеет его толщина. Так, например, слой толщиной 0,3 м промерзает до температуры $-5^{\circ} \mathrm{C}$ в три раза быстрее чем 
слой толщиной 0,6 м. Температура атмосферного воздуха также влияет на скорость формирования льдопородной плотины. Так, на проморозку слоя толщиной 0,5 м при температуре воздуха $-15{ }^{\circ} \mathrm{C}$ требуется более чем в два раза больше времени чем при температуре воздуха $-40^{\circ} \mathrm{C}$.

Таким образом, оптимизация технологических параметров послойного намораживания при строительстве мерзлой грунтовой плотины позволит формировать льдопородный массив с необходимыми прочностными свойствами, что будет способствовать повышению устойчивости сооружения и ускорению сроков его возведения.

Также технология послойного намораживания предложена для захоронения больших объемов твердых радиоактивных отходов (ТРАО). Выброшенные (более 20 лет назад) радионуклиды во время аварий на подземных ядерных взрывах «Кристалл» и «Кратон 3», произведенных на территории Якутии, стали причиной радиационного загрязнения значительных территорий, некоторые участки которых по степени загрязненности долгоживущими радионуклидами и изотопами плутония относятся к зонам чрезвычайной экологической ситуации и экологического бедствия. Растительность, грунт, почва в пределах этих участков относятся к твердым радиоактивным отходам, и в соответствии с действующим законодательством РФ должны быть переработаны и захоронены. Разработан способ захоронения твердых радиоактивных отходов в поверхностных курганных могильниках (ПКМ), на который получен патент России (№ 2134459) [6]. Для обоснования данного способа модифицирована математическая модель процесса послойного намораживания горных пород с учетом теплообмена с атмосферным воздухом. Результаты расчета показали, что в районах Крайнего Севера за зимний период

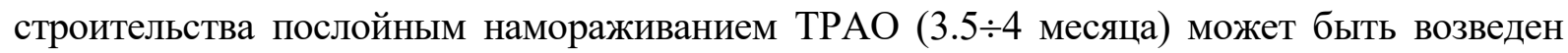
поверхностный курганный могильник высотой до 16 м. Целесообразным по условиям отсыпки и промораживания можно считать толщину слоя ТРАО, равную примерно 0,6 м, с влажностью не менее $60 \%$.

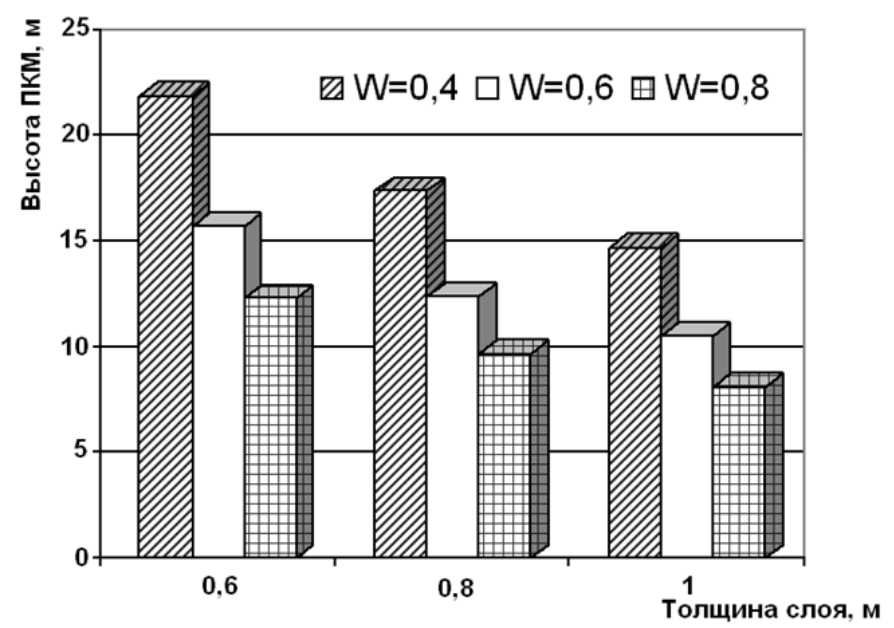

Рис. 3. Зависимость высоты ПКМ от толщины и влажности укладываемых слоев

Технологию послойного намораживания также можно использовать для захоронения небольших партий ТРАО в подземных горных выработках криолитозоны $[7,8]$.

$$
* * *
$$

1. Необутов Г.Г., Гринев В.Г. Разработка рудных месторождений с использованием замораживаемой закладки в условиях многолетней мерзлоты. - Якутск: Изд-во ЯНЦ СО РАН, 1997. -104 с.

2. Каймонов М.В., Хохолов Ю.А., Курилко А.С., Необутов Г.П. Методика расчета послойного намораживания пород при формировании льдопородного массива в горных выработках // Горный информационно-аналитический бюллетень. - 2003. - № 9 - С. 47-49. 
3. Хохолов Ю. А., Мамонов А. Ф., Зубков В. П. Оптимизация формирования льдопородного массива в горных выработках // Горный информационно-аналитический бюллетень. - 2004. - № 10 - С. 103-107.

4. Бураков А.М., Ермаков С.А., Каймонов М.В., Курилко А.С., Хохолов Ю.А. Технологические особенности строительства дражных полигонов в условиях россыпного месторождения криолитозоны // Горный информационно-аналитический бюллетень. - 2006. - № 8 - С. 271-276.

5. Курилко А.С., Ермаков С.А., Хохолов Ю.А., Каймонов М.В., Бураков А.М. Моделирование тепловых процессов в горном массиве при открытой разработке россыпей криолитозоны. - Новосибирск: Академическое изд-во «Гео», 2011. - 140 с.

6. Патент RUS 2134459, МПК6 G 21 F 9/24. Способ захоронения твердых радиоактивных отходов в зоне многолетней мерзлоты / В.В. Киселев, Ю.А. Хохолов; заявитель и патентообладатель ИГДС СО РАН. №97113864/25; заявл. 12.08.97; опубл. 10.08.99, Бюл. № 18.

7. Патент RUS 2263985, МПК6 G 21 F 9/34. Подземный бесконтейнерный способ захоронения твердых источников радиоактивного излучения в отработанных подземных горных выработках криолитозоны / В.В. Киселев, Ю.А. Хохолов; М.В. Каймонов; заявитель и патентообладатель ИГДС СО РАН. №2003125163/06; заявл. 11.08.03; опубл. 10.11.05, Бюл. № 31 .

8. Киселев В.В., Хохолов Ю.А., Каймонов М.В. Использование горных технологий и выработанного пространства рудников криолитозоны для захоронения твердых радиоактивных отходов // Горный информационно-аналитический бюллетень. - 2006. - № 3. - С. 129-134.

\section{Dmitrienko N.A., Avdeeva T.G., Alekseenko J.V. The research of methods and development of the system for Twitter messages sentiment analysis}

Don State Technical University

(Poccuя, Shakhty)

doi: $10.18411 / \mathrm{j}-31-01-2018-58$

idsp: 000001:lj-31-01-2018-58

\section{Abstract}

The article describes the development of a program for twitter sentiment analysis based on machine learning methods. The approaches used to determine the key of the text are considered. The analysis of current methods for determining sentiment analysis and vector space models of text presentation were provided. Three algorithms for the classification of texts by tonality were implemented: naive Bayesian algorithm, random forests, and logistic regression. During the testing of algorithms using the ROC curve, the most effective one was determined.

Keywords: machine learning, vector space model, naive Bayesian classifier, random forests, logistic regression.

Recently, social networks have grown rapidly on the Internet, such websites as Facebook and Twitter have become extremely popular since their first appearance. Nowadays millions of people share their thoughts about events happening in the world with their friends and followers on social networks.

One of the features of such social networks is the search for the necessary contacts and the establishment of connections between people. Sentiment Analysis can be used to analyze the history of user messages.

Recognizing texts marked with emotional labels is one of the classification tasks. This task can be applied not only for the classification of text, but also for tasks of artificial intelligence. Sentiment analysis is a field of computer linguistics, which deals with the allocation of emotionally labeled vocabulary or author's emotional evaluation from texts. Applying sentiment analysis commercial companies can find out the opinion of buyers about a product. This data can be used to improve the quality of the product, to determine the key audience, as well as to find the main advantages and disadvantages of competitors.

At the moment, there are two commonly used approaches to the sentiment analysis problem: the first approach is based on machine learning methods; the second one is called sentiment vocabulary-based approach 